\title{
Pragmatics of Ostensible Invitations in Iraqi Arabic: Function Analysis
}

\author{
Basim Jubair Kadhim ${ }^{1 *}$, Fareed Hameed Al-Hindawi² \\ ${ }^{1}$ Islamic University College, Department of English, Holy Najaf- Iraq \\ ${ }^{2}$ University of Babylon, College of Education for Human Sciences, Department of English, Babylon-Iraq
}

Corresponding Author: Basim Jubair Kadhim, E-mail: basimjubair1984@gmail.com

\section{ARTICLE INFO}

\section{Article history}

Received: September 19, 2017

Accepted: November 13, 2017

Published: December 30, 2017

Volume: 8 Issue: 6

Advance access: December 2017

Conflicts of interest: None

Funding: None

\author{
Key words: \\ Pragmatics, \\ Ostensible Speech Acts, \\ Ostensible Invitations, \\ Social Variables, \\ Iraqi Society
}

\begin{abstract}
This paper deals with the pragmatic functions of ostensible invitations as used by Iraqi Arabic speakers. Iraqi society is known of the traditions in which pragmatic language is highly considered that Iraqi Arabic speakers use speech acts in order to pay compliments among each other. The issuance of various ostensible speech acts is to convey other purposes than those conveyed by the genuine ones. It is believed that it is vital to dig deep in the functions of the speech act of invitation as this speech act is mostly used by the Iraqi Arabic speakers in an ostensible manner. So, depending on a test formulated and administered to Iraqi Arabic speakers represented by college students, data have been collected and analyzed to show the strategies and functions used peculiarly by Iraqi Arabic speakers in addition to those stipulated by Clark and Isaac whose model is adapted in the analysis. In terms of the strategies used in addition to the seven ones mentioned in the model, new ones emerged and are believed to be peculiar to the Iraqi Arabic speakers, for they are strongly related to the social norms of the Iraqi society. On the level of pragmatic functions, Iraqi Arabic speakers tend to use ostensible speech act of invitation for various purposes; chief among them are compliment, polite strategy, mitigation devices and others.
\end{abstract}

\section{INTRODUCTION}

Widdoson (2007: 14) argues that being able to communicate is to have two layers of linguistic knowledge: one is the knowledge that is simply encoded by using language, and the other is how the encoded language which is used in an appropriate context.

Of late, traditional approaches to speech acts have got weaker, while insincere or non-serious speech acts studies turn even stronger. In their treatment of speech acts, Austin (1965), Searle $(1969,1976)$ and Bach and Harnish (1979) do not tackle the issue of using language for non-serious purposes in a context that gives another kind of meaning which is completely different from the user's meaning. Relying on non-serious use of language argued by Goffman (1976), pragmatic insincerity has come to use. It is defined by Utsumi (2007: 508) as violating such pragmatic principles as maxims of cooperative principle and/or some of the felicity conditions of the speech acts in particular contexts for reasons of speaker's indented meaning.

Ostensible, insincere speech acts belong to the insincere use of language in particular contexts. Some speech acts include both sincere and insincere acts such as invitations, offers, compliments. etc. (Clark and Isaac, 1990: 2). Ostensible speech acts are defined as those speech acts that are issued for reasons of tacit rather than propositional content (ibid). In other words, they are used within what is discussed by (Clark and Gerrig, 1984) under pretense: the speaker pretends some other attitudes through the violation of pragmatic principles. In such speech acts, speakers pretend a pragmatically insincere ostensible speech act (Pinto, 2011: 215-38).

One of such pretended, insincere, ostensible speech acts is that of inviting. This type of speech acts has been dealt with by many scholars (Clark and Isaac, 1990; Eslami, 2005; Nodoshan, 2006). Most of them have treated such class of speech acts under the violation of sincerity condition of speech acts with regards to some social variables. In cultures as Arabic ones precisely the Iraqi culture, it is not only sincerity that is violated, but also other pragmatic principles are violated as pretense in addition to the pragmatic insincerity as introduced by (Utsumi, 2007: 508).

Accordingly, Iraqi Arabic speakers use ostensible speech acts of invitation with any kind of compliment at any level of propositional content. They use such an act to show deference, polite rituals, or to abide by some norms that society imposes. Ostensible speech act of invitations is one of the highly frequented speech acts used by Iraqi Arabic speakers. It reflects many social as well as pragmatically intended attitudes. This indirect, implicit, ostensible speech act is employed as a strat- 
egy to show generosity, sociality, politeness, impoliteness, or terminating a conversational exchange., etc.

As an umbrella strategy, the ostensible speech act of invitation contains various sub-strategies through which such speech act is produced (Clark and Isaac, 1990: 3). The strategies are utilized according to the context of situation; some strategies are peculiar to particular contexts, while others cannot be applied to the same contexts. These choices of what strategy to use depends on functions for which the ostensible invitations are extended. Hypothesizing these functions, they are mostly used as a pragmatically intended strategy in order to show particular tacit purposes.

The issue of pragmatic functions of such kind of speech acts has not been tackled yet at levels of pretense and pragmatic insincerity, and consequently ostensibility of speech act of invitation in Iraqi Arabic is not given its due attention. The present paper addresses the pragmatic treatment of speech act of ostensible invitations in Iraqi Arabic and the pragmatic functions of the speech act in question, indicating the strategies of extending ostensible invitations by Iraqi Arabic speakers and the reasons behind the speaker's commitment to social and polite norms when issuing such kinds of speech acts as invitation.

The paper aims at finding out the linguistic realizations (the pragmatic strategies) used to issue the speech act in question through stating the goals behind using it. It also aims at exploring the use of ostensible invitation as a speech act used by Iraqi Arabic speakers.

Based on the aforementioned aims, it is hypothesized that: Iraqi Arabic speakers use ostensible speech acts of invitation in many situations for reasons of prestige or other social considerations; it is more used as a way of showing polite rituals for specific occasions; and language is used non-seriously.

After giving a sufficient theoretical account regarding the topic in question, data are collected from different contexts represented by college students. The subjects are given a test formulated to achieve the aims set above. The present paper is of use sociolinguists concerning with language use from cultural perspective and also the textbook designers by including the phenomenon of ostensible speech act in textbooks for its increasing significance in terms of everyday life as a communicative acts.

\section{PRETENSE THEORY}

Clark and Gerigg (1984) introduce a theory regarding non-serious use of language called "Pretense Theory". They argue that using language non-seriously is that utterances are not in their actual intended meaning. Rather, speakers assume that they have different role from those intended ones (ibid: 4).

"A speaker pretends to be an injudicious person.. the speaker intends the addressee to discover the pretense and thereby see his or her attitude toward the speaker" (ibid: 12).

As a matter of getting away from one's own utterance as mentioned in the argument above, ostensible speech acts can be included under pretense in terms of production and intention. As such, the addressor uses a voice different from that of his or her own, and in return the addressee has the chance to find out the real, intended meaning of the addressor's attitude. Pretending to be someone else's voice is employed for several reasons: social, prestigious, politeness., etc.

Clark and Gerrig (ibid: 124) distinguish between two layers of the speaker's intention: the layer of reality meaning that the participants partake common ground, and the layer of pretense meaning that they assume roles different from their original in order to show particular attitudes

There should be what is called "Joint Pretense" whereby the speaker pretends, tests the pretense against the contextual factors taking into account the common ground, and finally the addressor join through common ground and context to recognize the attitude of the addressor as non-serious or ostensible (ibid).

\section{PRAGMATIC INSINCERITY}

Pragmatic insincerity is defined according to Utsumi (2007: 508) as the intended violation of one of the pragmatic principles: violation of one or more felicity conditions governing speech acts, one or more maxims of the cooperative principles governing conversations, or one or more strategies of politeness principle. In some occasions, overlapping violation of the pragmatic principle takes place altogether.

In terms of violating one or more felicity conditions of speech acts, Eslami (2005: 26) argues that infelicitous utterances (as mentioned by Austin 1962) are those speech acts having one of the felicity conditions unachieved. This is purposely done by speakers to implicate one attitude or another. Based on the aforementioned argument, such example as:

"would you like to have some tea?",

which is said to a person who breaks a meeting, is a speech act of inviting. However, such a speech act is not a felicitous one, for one of its felicity conditions is intentionally violated, more precisely sincerity condition. This infringement is pragmatically used by the speaker as discussed by Lyons (1977: 157) that when the utterance is used as invitation in an inappropriate context and the speaker knows that it is not the time for tea and the hearer does so, the invitation must be used for another reason which might be an order, in a mitigated way, to be dismissed.

At the level of violating one or more maxims of the cooperative principle, when pragmatically insincere, the maxim of quantity is flouted for the speaker's intentional purpose rather than propositional one (Utsumi, 2007: 508). This maxim says: make your contribution as informative as is required and do not be more informative than required. Accordingly, issuing such speech act of inviting as in the following example:

"Are you interested in having lunch some day?",

flouts the quantity maxim. The utterance above which represents a speech act of inviting lacks information for the addressee to fully understand the utterance as a genuine invitation. As such, the addressee receives such an utterance as a flouting to the quantity maxim because there is no mention about such felicity conditions of the speech act of inviting as the inviter, the time and the place of the invitation, or felicity conditions as mentioned by Levinson (1983: 346). This 
results in what Leech and Thomas (1990: 181) call "Pragmatic Implications". Consequently, such invitation will not be considered as genuine; rather, it will be taken as an invitation functioning as courtesy.

The third pragmatic principle that could be violated is when using linguistic realizations which are not in the conventional range of pragmatic meaning (Utsumi, 2007: 509). According to Brown and Levinson (1987) model of politeness, violation of one or more strategies yields in pragmatic insincerity. The strategy saying "be over-polite" is one of the politeness strategies violated for the purpose of being pragmatically insincere. The following example is more illustrating:

In a situation where a mother and daughter, in an event of invitation: the mother invites the daughter to have her dinner, the daughter does not come to have dinner. The mother keeps calling her daughter in vain. After finishing the dinner, the mother says:

"Would you mind if I with due respect invite you to have your own dinner?"

By using the above over-polite utterance, such an invitation lacks sincerity due to the violation of the conventional pragmatic implicature through using the politeness strategy "over-polite", in which the mother conveys her scorning or ironizing attitude towards her daughter indirectly.

To sum up, it can be argued that putting together: pretense theory and pragmatic insincerity can serve as a general strategy of ostensible language. In other words, pretending to use utterances which represent a property of communicative acts that crucially turn on the speaker's attitudes through using utterances that do not correspond to the hearer's propositional or truth-conditional content, and using pragmatically implicated utterance through violating the pragmatic principles of felicity conditions, maxims of cooperative principle and politeness strategies lead to non-serious category of speech acts which convey multi-purpose types of communicative acts peculiarly used by particular social groups.

\section{OSTENSIBLE SPEECH ACTS}

Within the theory of pretense, one of the essential conditions of the speech acts to be felicitous (i.e. sincerity) is pretended. However, pretending the sincerity condition does not mean that the utterance is pragmatically insincere. It needs other circumstances to be taken non-seriously (Eslami, 2005: 26).

In a category introduced by Clark and Isaac (1990), different from those introduced by Austin 1969, Searle 1976, and Harnish 1979, there are the ostensible speech acts; direct or indirect. What distinguishes ostensible speech acts is the umbrella property of pretense, where speakers issue speech acts pretending to be genuine while in addition to other related properties, they are pretending to convey other off-record purposes (ibid: 493). Accordingly, for the utterance to be accounted as pretense, the addressee should take the utterance as pretense. So doing, there are several defining properties to ostensible speech acts. These properties are with/under pretense to yield ostensible speech acts (ibid: 495-7).

Adapting an operational definition to this class of speech acts, it is based on Nodoushan's (2006: 10) account of osten- sible speech acts. Ostensible speech acts are utterances that may take a form of genuine speech acts such as invitation, question, request. etc., but they function as off-record for some other unsaid purposes.

Speakers use such speech acts in order to avoid making their thoughts explicit and expect the hearer to infer the attitudes (Gibbs, 2000: 289). Ostensibility in speech acts is constituted via mutually recognized pretense whose purpose is off record. Analyzing the definition above and to be more illustrative, it is worth mentioning the properties of ostensible speech acts as introduced by Clark and Isaac (1990) and reiterated by Link and Kreuz (2000):

1. Pretense: the speaker should use utterances to pretend that $\mathrm{s} /$ he produces genuine speech acts. However, the pretense is a joint pretense, as discussed in section (1), which means that pretense is to be pragmatically insincere in order to be recognized by the addressee.

2. Mutual Recognition: the pretended, pragmatically insincere utterance should not be recognized by the speaker only, but it should be recognized by the addressee as well.

3. Collusion: after the speaker makes it possible for the addressee to recognize the insincere, pretended utterances, s/he expects the addressee to collude with the utterance. Collusion is to react in an appropriate way, meaning to give ostensible utterances.

4. Ambivalence: this is represented by the embarrassing question of "do you really mean it?". The speaker then could not honestly answer "yes" or "no". Answering "yes" means that the speech act turns to be insincere and vice-versa. However, for some tacit purpose, the speaker is neither sincere nor lying. The speaker is rather pragmatically insincere, meaning that either answer is possible. The perlocution is not that of the speech act issued, but of other pragmatic purpose.

5. Off-record Purpose: being ambivalent, the speaker uses ostensible speech acts to make them open to plausible interpretations in a way that the speaker is not accountable for the speech acts issued.

The following example can demonstrate the properties of ostensible speech acts:

In a cafeteria, the professor who is having tea meets one of his students. After greeting, the professor invites the student to share tea with him.

- The professor: Hello, it is good tea.

- The student: many thanks sir. That's very kind of you.

In accordance with the example and its contextual factors above, it is clear that the professor invites the student and the student has to decline the invitation. According to the context, the professor is having one cup of tea which is by nature cannot be shared with, and he has power on the student, so as a matter of courtesy or getting friendly to the student, the professor pretends (i.e. pretense) to be at the same distance of the student and extends an invitation to the student, indicating that the invitation is not a genuine one through wanting the student to share the same cup. The student, on the other hand, comes to realize (i.e. mutual recognition) that the invitation is not a real one for the same contextual 
factors: the lack of the felicity conditions of the invitation (propositional content which leads to insincerity) and social distance between the professor and the student. Accordingly, the student colludes (i.e. collusion) with the invitation of the professor appropriately, taking it as other type of speech acts of being friendly and showing respect than that of invitation. The professor will not be able to answer either "yes" or "no" to the question of the propositional content of the speech act, for he is pragmatically insincere as defined above. Rather, the professor uses such speech act of invitation to be friendly to the student according to the contextual factors.

\section{SPEECH ACT OF INVITATION (GENUINE \& OSTENSIBLE)}

To have a clear account on ostensible invitation, something about genuine one should be reviewed. Speech act of invitation is constituted of: preinvitations (Atkinson \& Drew 1979; Levinson, 1983) or leads (Wolfson, 1989). Such preinviations or leads are used by the speaker to build a ground or to prepare before issuing the speech act of invitation. Many utterances are used for this purpose as "Are you busy Thursday night?", "What are you going to do tonight?" (Clark \&Isaac, 1990: 499).

Wolfson (1989: 67) argues that invitations contains three requisites: a reference to time, place and a request for response. Yet, there is another type of invitations in which the leads are left open. Simply put, time is always indefinite, a response is not required and a modal auxiliary like "must", " "should" or "have" is always used. This type of invitation is called "ambiguous invitations" (ibid: 122).

Clark and Isaac introduce yet another reflection to speech act of invitation: ostensible invitations, claiming that it is different from that of Wolfson's ambiguous invitations, though they are similar in principle [my italics]. Therefore, ostensible speech act of invitation can be defined as those invitations that the speaker extends not to be taken seriously, but to accomplish some other unstated purposes, as indicated above (ibid: 2).

As one of the ostensible speech acts, ostensible speech act of invitation can be defined and distinguished from those genuine ones under the same five properties of most ostensible speech acts mentioned in section (4). They are: pretense, the inviter only pretends to extend sincere invitation, and the invitee is only pretending to response (usually refuse) to the invitation; mutual recognition, the inviter intends the pretense to be recognized by the invitee according to what the inviter wants; collusion, invitee is expected to collude with the inviter's pretense; ambivalent, if the inviter was asked "Do you really meant it?", neither positive nor negative answer is given; and finally, off-record purpose, invitations are extended for off-record purposes related to the various cultural diversifications in order to give politeness account as introduced by Brown and Levinson (1987) (Eslami, 2005: 40).

As such, ostensible invitations have the two layer of communication: a top layer where the inviter issues an invitation and the invitee responds accordingly; and a bottom layer where both the inviter and the invitee are collusive to each other with mutual recognition that the top layer is only pretense (Widiss, 1996: 110).

It can be argued clearly that some of these properties are related to the speaker and others are related to the hearer. Therefore, ostensible speech act of invitation is composed of stages represented by the chronological order of the properties. The Figure 1 below can be more illustrative:

The speaker pretends to issue an invitation by the pretense and pragmatic insincerity, and then, the speaker issues an ostensible speech act of invitation to be mutually recognized. This can be called "Issuance Satge". The second stage "Collusive Stage" is that the hearer colludes with the speaker through taking the meaning that the speaker has in mind and be ambivalent, i.e. the hearer does not ask the speaker about the sincerity of the speech act issued. The final stage (third stage) has the effect of the speech act which can be achieved in order for the ostensible invitation to be fulfilled.

Based on Clark \& Isaac (1990), there are seven features for ostensible invitations. These features clearly manifest the strategies employed by the inviters to signal to the invitees that the invitation is an ostensible one. Whenever the inviter (A) ostensibly invites the invitee (B) to the event (E), the inviter may do one or more of the following:

1. A makes B's presence at E implausible.

2. A extends invitations only after they have been solicited.

3. A doesn't motivate invitation beyond social courtesy.

4. A is vague about arrangements for event $\mathrm{E}$.

5. A doesn't persist or insist on the invitation.

6. A hedges the invitation.

7. A delivers the invitation with inappropriate cues.

Therefore, implausibility, solicitation, not motivating, hesitation, not insisting, hedging, and inappropriate cues are the pragmatic strategies, under the umbrella of pretense and pragmatic insincerity, for producing ostensible invitations (Clark, 1996: 381).

In performing an ostensible invitation, the speaker is likely to use certain strategies to indicate that the invitation is ostensible. The aim of performing ostensible invitation is not to establish the invitation, but to fulfill social, ritual and interacting functions to achieve a harmonious human relationship. Accordingly, it can be concluded that the above mentioned strategies might represent a particular social group. There could be more or less than these strategies depending on the society in which ostensible invitations are extended.

Accordingly, perlocutionary force of ostensible speech act of invitation is fulfilled in the five stages mentioned above, along with the issuing strategies.

\section{IRAQI SOCIETY \& INVITATION EXTENDING}

As a matter of analyzing the ostensible speech act in question, Savil-Troike (1997: 126) argues that it is imperative to have some account about any ethnographic analysis of communicative event, starting with defining speech community, social organization, and ending with the prominent cultural hallmarks. Thus, it is important to present an account about Iraqi society and how invitation is made.

Iraq is characterized by a tribal society which is centered on family and the attitude towards it. Brothers, sisters, 


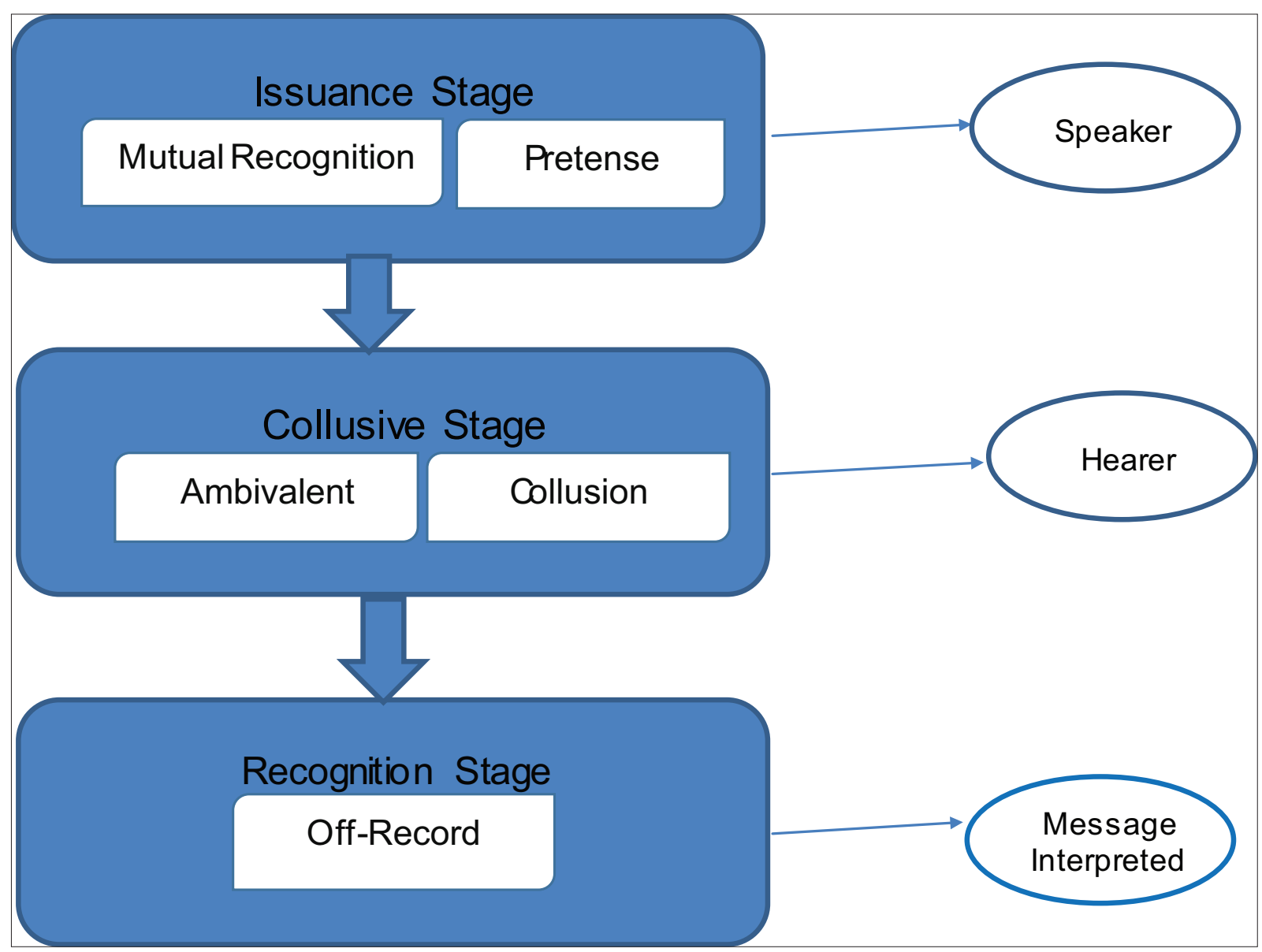

Figure 1. Stages of Ostensible Speech Acts

friends and even neighbors will remain in strong contact with one another. One way through which Iraqi people express their feelings towards each other is by inviting one for a particular event as in all Arab countries. The invitation starts with the inviter (host) who invites the invitee(s) (guest(s)) to some event (dinner, party, meal, drinks. etc.), as outlined by Levinson (1983: 346). Then, the inviter tries to be highly hospitable in order to save his/her face in regard to the inviter. Afterwards, the invitee appreciates the invitation and the good hospitality, ending with praying for the inviter to have the best living level, as a way of thanking the host.

The Iraqi society has a special pattern of inviting. When two people engage in a context in which one is keen to invite the other, the inviter insists on invitation and the one who is invited should bashfully reject the invitation but in reality accepts it later. This staged process depends on some contextual factors like the insistence on the time and event of the invitation and the tone of extending the invitation. Al-Khatib (2001: 190) argues that an invitation which lacks such elements as time, place and the utterance that has insistence making the invitation sincere is not a serious invitation. Within the passage of time, Iraqi society used to employ different functions to some social attitudes as invitations rather than those original ones (Al-Wardi, 2001: 7). Put differently, some utterances are emptied from their propositional content to be filled with other implications conventionally used by some group of people. Such functions are utilized as intend- ed, pragmatic interactional strategies of keeping rapport and face saving acts.

The Iraqi society, by hypothesis, come to extend genuine invitations lacking their own felicity conditions [see 4] in order to be ostensibility used for pragmatic purposes. This type of speech act (ostensible speech acts) is social-context dependent. It can be argued that this phenomenon cannot be addressed without considering social norms and variables discussed by Brown and Levinson (1987). They have direct impact on the way of issuing, accepting and refusing the invitation. These parameters by which the ostensible speech act of invitation could be influenced are: the social distance (D) between the inviter and the invitee, the relative power (P) between them, and the rank (R) of imposition.

\section{DATA: COLLECTION \& ANALYSIS}

In this section, data are collected from hundred Iraqi college students used as informants. Afterward, the students are given a test formulated to reach the objectives of the paper. The test is of two questions: question one is a production one used to show the strategies used by Iraqi Arabic speakers to extend ostensible invitations; and question two tackles the reasons why ostensible invitations are used (i.e. functions of ostensible invitations).

After administrating the test, the five properties or three stages, as argued by the present paper, strategies and social 
variables discussed by Clark and Isaac (1990) are used as model to be followed in the analysis of data.

\section{Section One Analysis}

In this section, question one is analyzed. Situations of the question are formulated in accordance with the strategies in the model adapted (i.e. Isaac \& Clark) and amended in this paper. Situations are also used to measure the types of strategies used by Iraqi Arabic speakers in relation to context of situation and social variables. The social status is divided into high to low, equal status, and low to high.

The question is composed of ten situations to find out the type of strategies used. Particular subjects are asked to answer the issuance stage and others are asked to respond to what has been issued. This is vital to reach out the three stages of ostensible invitations as modified by this paper. Contextual factors and social variables are given in the situations to elicit information about the subjects' use of strategies of ostensible speech act of invitation.

Situations to be under analysis are only those which show use of other strategies than those in the model adapted. In other words, the strategies of the model will not be analyzed for space and monotonous reasons. Rather, the strategies of the model will be represented in Table 1.

Situation 1: you are on your way back home with a friend of yours. You arrive home before your friend. What will you say to invite your friend?

- Inviter: Tiji titfadhal wyana? (Will you come over to my house?).

- Invitee: Askurak, maa alsalama. (thanks, bye bye).

In the situation above, informants use different linguistic realization which are all categorized under speech act of requesting to issue the ostensible invitation, i.e. the inviter asks the invitee to have something. In the first stage, the inviter pretends the attitude of invitation and indicate, through speech act of request, that the invitee should recognize that the invitation is unreal. As in the situation, both friends are heading home, and asking each other to be invited is not suitable to sincerely invite each other.

In the second stage, the invitee refuses the invitation normally. The refusal is not sincere. It is rather a result of the mutual recognition that the inviter is insincere (i.e. the inviter violates the sincerity condition of the speech act of requesting), and the invitee colludes with the insincerity of the inviter. The collusion leads to the third stage, i.e. the intended meaning of the inviter which is an off-record purpose.

Situation 2: at your office, you are drinking a cup of tea. Someone whom you are acquainted with enters the office. You do not have other cups than the one you have. What would you say?

- Inviter: khush chai! (Good teat).

- Invitee: fadhil minak, maagdar (It is nice of you, but I cannot.)

In the first stage, the inviter pretends to offer the invitee an invitation, but at the same time he intends to make him recognize that the invitation is ostensible through the strategy employed: speech act of stating which is uttered under different linguistic realizations varied according to the informants. The speech act lacks sincerity condition to be achieved as genuine invitation.

The invitee, after mutually recognized that the inviter is insincere, colludes with the inviter and does not question the sincerity of the invitation (collusive and ambivalent stage). This collusion is manifested through the invitation refusal by the invitee. Accordingly, the pragmatic intention of the inviter is accomplished.

Situation 3: you want to invite your close friends with whom one person is standing. You have no intention to invite that person. What would you say?

- Inviter, after inviting his close friends: tabaan alkul yagdar yaji (and surly, all can come over)

\section{- Invitee: Allah karem, Ashoof (I'll see to it.)}

In this situation, the inviter employs speech act of statement indicating generalization. Using generalizations, the inviter opens stage one in pretending that he extends an invitation, but in fact he indicates that the invitee should recognized that the invitation is not meant. Speech acts used to make generalizations lacking one of the felicity conditions: sincerity condition.

The invitee, however, continues in the second stage by colluding with the generalization of the inviter, and he does not ask whether the invitation is sincere or not, an obvious matter manifested via violating the felicity conditions of speech act of invitations for pragmatic purposes. Hence, the perlocutionary effect of the speech acts used is achieved.

\section{Section Two Analysis}

In this section, the second question is analyzed. The question contains ten situations including the seven strategies as well as the three ones discovered in the present paper. It is administered after analyzing question one so that all the strategies employed are represented in the test as a matter of reaching consistent justifications. In this question, the informants are required to give the reasons why issuing such invitations in such contexts and social variables (i.e. functions of ostensible invitations). The social variables are arranged in same way as in the first question. The situations along with the ostensible invitations as well as the functions that have been given by informants are shown in Table 2 below:

\section{FINDINGS AND DISCUSSION}

In question one which is concerned with the strategies of issuing ostensible speech act of invitation, informants show the highest percentage in the use of strategies: the inviter hedges the invitation $(80 \%)$, the inviter does not persist or insist on the invitation ( $76 \%$ ), and the inviter delivers the invitation with the inappropriate cues $(71 \%)$. In terms of social variables manifested in the items for which these three strategies are employed, they are varied in age, gender and social status. In regards to the strategy not insisting on invitation, it is greatly used high status. As for the strategy "hedging the invitation", its peak use is demonstrated equal class. The third strategy "inappropriate cues" is employed high status.

The strategies "the inviter does not motivate beyond social courtesy, the inviter is vague about arrangements of 

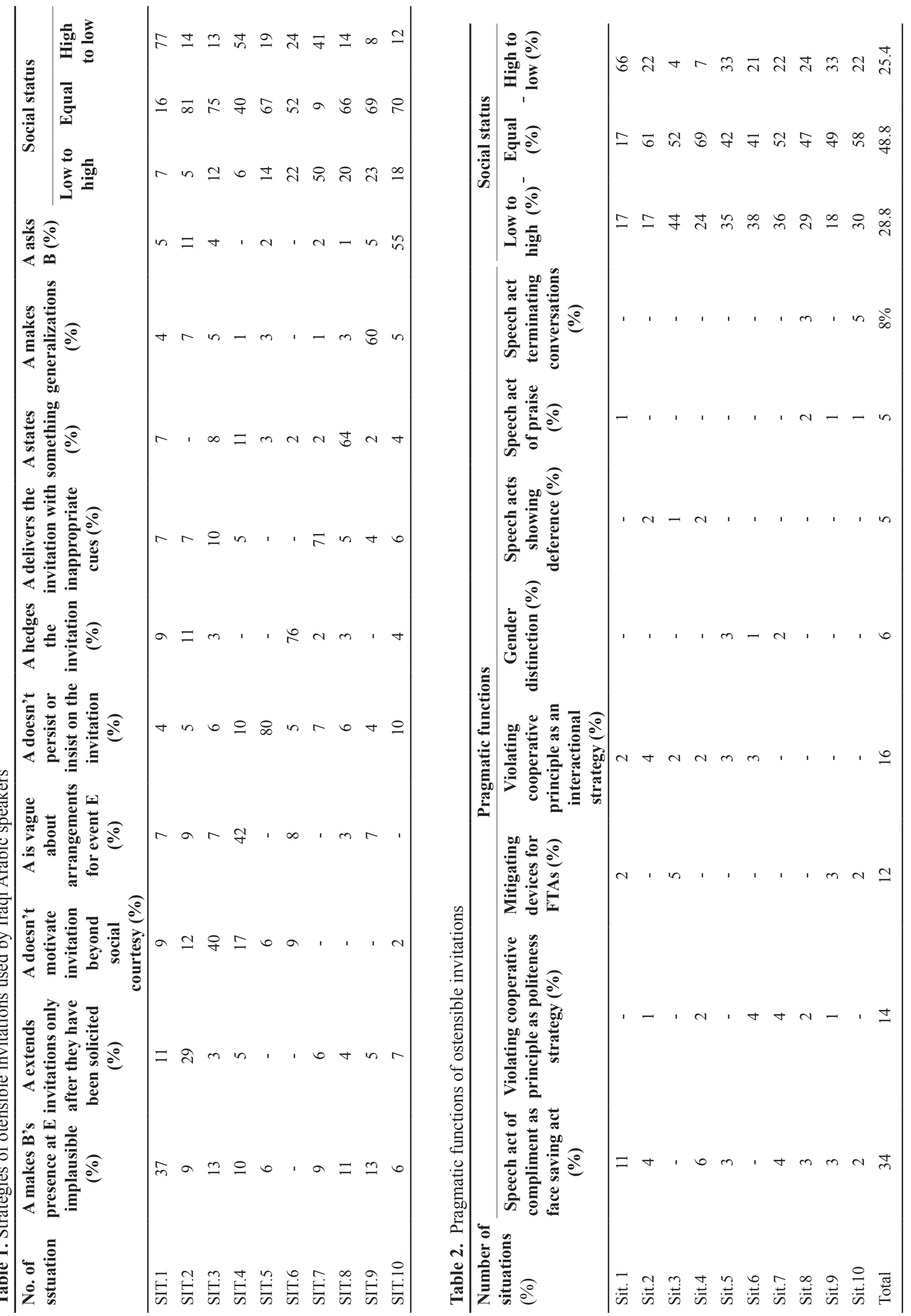
event E" show less use by informants (i.e. \%40 and \%42). These two less-used strategies are employed bydifferent social classes: the strategy "the inviter does not motivate beyond social courtesy" is used by equal social status, while "the inviter is vague about arrangements of event E" is used by high class. The strategy "not motivating" is highly used by high status.

The least remaining strategies used are: implausibility and solicitation of the invitation. These are rarely used by Iraqi Arabic speakers (i.e. they are $37 \%$ and $29 \%$ ). The implausibility is utilized by high status. The solicitation is employed equal status. The Iraqi society has a direct impact on using these strategies; informants' social norms necessitate that they are not allowed to ask to be invited unless among very strong relation [see section 6].

Besides the strategies of the model adapted, considerable ones are utilized by the informants: a. the inviter issues a speech act of statement $(64 \%)$; b. the inviter makes generalizations $(60 \%)$; c. the inviter issues speech act of requesting the invitee $(55 \%)$. These are issued by the informants with high frequencies according to the contextual factors and social variables given in the test. The strategy of speech act of stating is employed by equal status. The second strategy: making generalizations are employed by high status. Concerning the speech act of requesting, it is utilized by equal and low classes [see Table 1]. The use of these three strategies is sociolinguistic specific to Iraqi Arabic speakers, meaning that these strategies belong to culturally framed society in which ostensible invitation is issued for other purposes than genuine invitation.

The data in question one are also analyzed under the stages of ostensible speech act of invitation (as formulated by the present paper). Only issuance stage is demonstrated in the linguistic realizations that the informants issued. In other words, the sub-stages pretense and pragmatic insincerity (represented by mutual recognition) are used in issuance stage. Such utilization shows that the inviter pretends propositional attitudes other than those which are intended to be mutually recognized by the invitee. The collusive and recognitive stages are manifested via the responses that are issued by other test-givers to show whether the invitations are ostensibly issued or not.

Question two, which is related to the functions of ostensible speech act of invitation, shows eight functions given by the informants:

1. Compliment: the highest percentage $34 \%$ of using ostensible speech act of invitation is that it is used as compliment attitude. It is normally used by equal status. As mentioned in section six that the Iraqi society uses compliments and tribal manners a lot.

2. Polite strategy through violating $\mathrm{CP}$ maxims. This has the percentage $14 \%$. It is mostly used by equal social status. This function is related to another social characteristic in the linguistic norms of the Iraqi Arabic speakers.

3. Ostensible invitations are justified to be used as mitigating devices for face threatening acts. This function comes in the third place, having the percentage $12 \%$ which is utilized by equal status. This is connected to the particular patterns used by Iraqi Arabic speakers when issuing face threating acts as indicated by (AlWardi, 2001).

4. Keeping interactional rapport: this is accomplished through violating the $\mathrm{CP}$ maxims. This function has $16 \%$ ratio, used by informants of equal status.

5. Gender distinction: this is another function manifested by ostensible invitations is employed by face saving act. The percentage of this function is $6 \%$ used by equal status females to be distinguished from males.

6. As a strategy of showing deference, some speech acts conveying ostensible invitations are employed. This function has a percentage of $4 \%$ used by equal status.

7. Speech act of praising can be conveyed through ostensible invitations. This is employed by $5 \%$ equal status.

8. Ostensible invitations can be extended to imply speech act of requesting which is used to terminate conversation. This has $8 \%$ percentage utilized by equal status.

\section{CONCLUDING REMARKS}

The paper has come up with the following conclusions:

1. Ostensible speech act of invitation is a socio-pragmatic norm which is highly utilized by Iraqi Arabic speakers: it is mostly consumed by equal social status.

2. The most frequently employed strategies by Iraqi Arabic speakers to issue ostensible speech act of invitation are:

a. The inviter hedges the invitation;

b. The inviter does not persist or insist on the invitation; and

c. The inviter delivers the invitation with inappropriate cues.

3. New strategies are manifested by the informants which seem to be peculiar to Iraqi Arabic speakers to issue ostensible invitations. These strategies are:

a. The inviter makes statements;

b. The inviter makes generalizations; and

c. The inviter asks the invitee.

4. Ostensible invitations have eight pragmatic functions:
a. Compliment
b. Polite strategy
c. Mitigator
d. Interactional (phatic communion) strategy
e. Gender distinction
f. Praising strategy
g. Deference strategy
h. Conversation terminator

\section{REFERENCES}

Al-Khatib, M. A. (2001) 'The Pragmatics of Letter-writing', World Englishes 20-2: 179-200.

Al-Wardi, A. (1965) A Study in Iraqi society. Reprinted: Beirut: Tigress and Euphrates Library 2009.

Atkinson, J. M., and Drew, P. (1979) Order in Court: The Organization of Verbal Interaction in Judicial Settings. London: Macmillan. 
Austin, J. (1962). How to Do Things with Words. Oxford: Clarendon Press.

Bach, K. and R. Harnish (1979). Linguistic Communication and Speech Acts. Cambridge: MIT Press.

Brown, P. \& Levinson, S. (1987) Politeness: Some universals in language usage. Cambridge: Cambridge University Press.

Clark, H. H. and Isaacs, E. A. (1990). “Ostensible Invitations." Language in Society. 19: 493-509.

Clark, H. L. and Richard J. Gerrig (1984) "On The Pretense Theory of Irony ".In Journal of Experimental Psychology: General by the American Psychological Association. Reprinted in Irony in Language and Thought.(2007)

Eslami, Z. R. (2005). "Invitations in Persian and English: Ostensible or Genuine". Intercultural Pragmatics (912). 453-480.

Geis, M. (1995). Speech Acts and Conversational Interaction. Cambridge: Cambridge University Press.

Gibbs, R. W., Jr. (2000). Metarepresentations in staged communicative acts. In D. Sperber (Ed.), Metarepresentations: A Multidisciplinary Perspective, (pp. 389-410). New York: Oxford University Press.

Goffman, E. 1976. "Replies and Responses." Language in Society. 5 (3): 257-313.

Kreuz, R. (2000). "The Production and Processing of Irony". Metaphor and Symbol, pp. 99 - 107.

Leech, G. and Thomas, J. (1990) "Language Meaning and Context: Pragmatics". An Encyclopedia of Language. London: Routledge.
Levinson, S. (1983) Pragmatics. Cambridge: Cambridge University Press.

Lyons, John (1977) Semantics. Vol. I \& II. Cambridge: Cambridge University Press. Reprinted in 1979 Macmillan press Ltd.

N. Coupland and A. Jaworski (eds) Sociolinguistics, pp. 126145. London: Ostensible Invitations in English and Farsi. Speech Communication 48.

Pinto, D. (2011) "Are Americans Insincere? Interactional style and politeness in everyday America". Journal of Politeness Research 7: 215-244.

Salmani Nodoushan, M. A. (2006). A Sociopragmatic Comparative study of Ostensible Invitations in English and Farsi. Speech Communication, 48(8), 903912.

Saville-Troike, M. (1997) 'The Ethnographic Analysis of Communicative Events', in N. Coupland and A. Jaworski (eds) Sociolinguistics, pp. 126-145. London: Macmillan press Ltd.

Searle, J. (1969). Speech Acts: An Essay in the Philosophy of Language. Cambridge: Cambridge University Press.

Searle, J. (1976) Classification of Illocutionary Acts., Language and society, 5:1-23.

Utsumi, A. (2000). Verbal Irony as Implicit Display of Ironic Environment: Distinguishing Ironic Utterances from Nonirony. Journal of Pragmatics, 32, 1777-1806.

Widiss, B. (1996). Obscure Invitations. Stanford: Stanford University Presśf.

Wolfson, N. (1989). Perspectives: Sociolinguistics and TESOL. New York: Newbury House Publishers. 